\title{
Electromagnetic Heating Methods for Heavy Oil Reservoirs
}

\author{
A. Sahni, M. Kumar and R.B. Knapp
}

This article was submitted to 2000 Society of Petroleum Engineers SPE/AAPG Western Regional Meeting Long Beach, $C A$

June 19-23, 2000

\section{May 1, 2000}




\section{DISCLAIMER}

This document was prepared as an account of work sponsored by an agency of the United States Government. Neither the United States Government nor the University of California nor any of their employees, makes any warranty, express or implied, or assumes any legal liability or responsibility for the accuracy, completeness, or usefulness of any information, apparatus, product, or process disclosed, or represents that its use would not infringe privately owned rights. Reference herein to any specific commercial product, process, or service by trade name, trademark, manufacturer, or otherwise, does not necessarily constitute or imply its endorsement, recommendation, or favoring by the United States Government or the University of California. The views and opinions of authors expressed herein do not necessarily state or reflect those of the United States Government or the University of California, and shall not be used for advertising or product endorsement purposes.

This is a preprint of a paper intended for publication in a journal or proceedings. Since changes may be made before publication, this preprint is made available with the understanding that it will not be cited or reproduced without the permission of the author.

This report has been reproduced directly from the best available copy.

Available to DOE and DOE contractors from the

Office of Scientific and Technical Information

P.O. Box 62, Oak Ridge, TN 37831

Prices available from (423) 576-8401

http:/ / apollo.osti.gov/bridge/

Available to the public from the National Technical Information Service

U.S. Department of Commerce 5285 Port Royal Rd., Springfield, VA 22161 http://www.ntis.gov/

OR

Lawrence Livermore National Laboratory Technical Information Department's Digital Library http://www.llnl.gov/tid/Library.html 


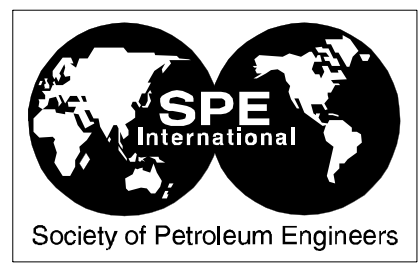

SPE 62550

\section{Electromagnetic Heating Methods for Heavy Oil Reservoirs}

Akshay Sahni and Mridul Kumar, Chevron Petroleum Technology Company, Richard B. Knapp, Lawrence Livermore National Laboratory

Copyright 2000, Society of Petroleum Engineers Inc.

This paper was prepared for presentation at the 2000 SPE/AAPG Western Regional Meeting held in Long Beach, California, 19-23 June 2000.

This paper was selected for presentation by an SPE Program Committee following review of information contained in an abstract submitted by the author(s). Contents of the paper, as presented, have not been reviewed by the Society of Petroleum Engineers and are subject to correction by the author(s). The material, as presented, does not necessarily reflect any position of the Society of Petroleum Engineers, its officers, or members. Papers presented at SPE meetings are subject to publication review by Editorial Committees of the Society of Petroleum Engineers. Electronic reproduction, distribution, or storage of any part of this paper for commercial purposes without the written consent of the Society of Petroleum Engineers is prohibited. Permission to reproduce in print is restricted to an abstract of not more than 300 words; illustrations may not be copied. The abstract mus contain conspicuous acknowledgment of where and by whom the paper was presented. Write Librarian, SPE, P.O. Box 833836, Richardson, TX 75083-3836, U.S.A., fax 01-972-952-9435.

\section{Abstract}

The most widely used method of thermal oil recovery is by injecting steam into the reservoir. A well-designed steam injection project is very efficient in recovering oil, however its applicability is limited in many situations. Simulation studies and field experience has shown that for low injectivity reservoirs, small thickness of the oil-bearing zone, and reservoir heterogeneity limits the performance of steam injection. This paper discusses alternative methods of transferring heat to heavy oil reservoirs, based on electromagnetic energy. We present a detailed analysis of low frequency electric resistive (ohmic) heating and higher frequency electromagnetic heating (radio and microwave frequency).

We show the applicability of electromagnetic heating in two example reservoirs. The first reservoir model has thin sand zones separated by impermeable shale layers, and very viscous oil. We model preheating the reservoir with low frequency current using two horizontal electrodes, before injecting steam. The second reservoir model has very low permeability and moderately viscous oil. In this case we use a high frequency microwave antenna located near the producing well as the heat source. Simulation results presented in this paper show that in some cases, electromagnetic heating may be a good alternative to steam injection or maybe used in combination with steam to improve heavy oil production. We identify the parameters which are critical in electromagnetic heating. We also discuss past field applications of electromagnetic heating including technical challenges and limitations.

\section{Introduction}

While steam injection may be an effective method for improving heavy oil production, there are certain situations where it may not work very well. These could be for:

1. Very deep formations, where heat losses in the wellbore are significant and the quality of steam reaching the formation is very low.

2. Thin pay-zones, where heat losses to adjacent (non oilbearing) formations may be significant.

3. Low permeability formations, where the injected fluid may have difficulty penetrating deep into the reservoir.

4. Reservoir heterogeneity, where high permeability streaks or fractures may cause early injected fluid breakthrough and reduce sweep.

5. Situations where generating and injecting steam may be environmentally unacceptable (example: through permafrost) or commercially uneconomical (in space limited offshore platforms).

In this paper we discuss alternative methods for heating heavy oil reservoirs, which may be economically viable alternatives to steam in certain situations. We describe two electromagnetic heating methods - low frequency electric resistive (ohmic) heating and high frequency microwave heating. We demonstrate the applicability of electromagenetic heating with two example reservoirs - one which has a thin sand zones separated by impermeable shale layers and another which has moderately viscous oil and low permeability.

For tar-sands or extremely high viscosity reservoirs, where the temperature effect on viscosity is significant, electromagnetic heating could be used as a pre-heating tool to create preferential pathways for steam injection. This would minimize the heat losses[1] during steam injection, and improve steam injection performance. 
Past studies[2-34] have shown some promise in the process, however there are few field applications of electromagnetic heating or comprehensive modeling efforts. Compared to other thermal IOR methods, electromagnetic heating still remains a peripheral technology, even though it the potential was recognized more than three decades ago.

\section{Electromagnetic Methods for Heating Oil Reservoirs}

Electrical heating of a formation can occur in a number of ways, depending on the frequency of the electrical current. In the high frequency range (radio frequency and microwave), dielectric heating prevails, and the dipoles formed by the molecules tend to align themselves with the electric field. The alternation of this field induces a rotational movement on the dipoles, with a velocity proportional to the frequency of alternation. The molecular movement may result in significant heating, as is seen in microwave ovens. When low frequency Alternating Current is used, it is the resistive or ohmic $\left(\mathrm{I}^{2} \mathrm{R}\right)$ heating which is dominant. A third method of electrical heating is inductive heating, where Alternating Current flowing through a set of conductors induces a magnetic field in the surrounding medium. The variation of the magnetic field, in turn, induces secondary currents, whose circulation in the medium generates heat.

In this paper we discuss and model low frequency electric resistive heating and high frequency microwave heating.

\section{Low Frequency Electrical Resisitive Heating}

Electrical resistive heating or ohmic heating may occur when low frequency alternating current flows through the reservoir, and electrical energy is converted into heat. In the simplest configuration (Figure 6), two neighboring producing oil wells may act as cathode and anode. A potential difference is applied across the two electrodes and an electrical path through the formation is provided by the formation (in-situ) water. As such, to maintain the electrical circuit, the formation temperatures should be kept below the boiling point of water (at the formation pressure).

A detailed review of the Ohmic Heating simulator used in this study is presented in References [28] and [29]. We present only a few key concepts in this paper.

Conservation of electric charge requires that:

$$
? J=Q
$$

where $\mathrm{J}=$ current density

$Q=$ electric charge injected or extracted at a location per unit time

$\nabla=$ gradient operator.

It is assumed that the time derivative of the volumetric charge density is negligible since the time dependent variation of the driving electric field is slow enough for capacitive effects to be neglected.

Also, from Ohm's Law

$J=-\sigma \Phi$

where $\Phi=$ electric potential

$\sigma=$ electrical conductivity

Waxman-Smits model [34] is used to capture the dependence of conductivity on temperature, saturation and lithology.

$\sigma\left(T, S_{w}\right)=\phi S_{w} \frac{\phi S_{w}}{\rho_{\text {ionic }}(T)}+B(T) Q_{v b}$

where

$\begin{array}{rll}\rho_{\text {ionic }} & = & \text { water resisitivity } \\ \mathrm{B} & = & \text { exchange cations equivalent conductance } \\ \mathrm{Q}_{\mathrm{vb}} & = & \text { bulk cation exchange capacity } \\ & = & 265[1-\phi] \text { equiv } / \mathrm{m}^{3} \text { for sands } \\ & = & 504[1-\phi] \text { equiv } / \mathrm{m}^{3} \text { for shales }\end{array}$

From Equation 3, it is evident that presence of water is a necessary criteria for low frequency ohmic heating, as with decreasing water saturations the conductivity decreases. The coupling of electrical heating with a regular finite-difference flow simulator (through the source term in the heat equation and also through the temperature and saturation dependence on electrical conductivity) is described in Reference [28].

\section{Features of the Simulation Model}

1. The simulation model is a Cartesian, three-dimensional model with $24 \times 24 \times 18$ grid blocks of $\Delta x=\Delta y=14.32 \mathrm{ft}$ and $\Delta \mathrm{z}$ is variable, with finer gridding near the horizontal wells (and electrodes).

2. The middle sand is 30 feet thick, whereas the top and bottom sands are 10 feet in thickness. The three sands are separated by two impermeable shale layers of 5 feet thickness.

3. Heavy oil has been represented as a single-component oil of $14.1^{\circ}$ API and molecular weight of 400 .

4. Heavy oil viscosity at the initial temperature of $95^{\circ} \mathrm{F}$ is $9541 \mathrm{cp}$. Viscosity - Temperature relationship is given in Table 1.

1. The sands in the reservoir model have $\mathrm{k}_{\mathrm{x}}=\mathrm{k}_{\mathrm{y}}=2,500 \mathrm{md}$, $\mathrm{k}_{\mathrm{z}} / \mathrm{k}_{\mathrm{x}}=0.5, \phi=0.36$, Initial reservoir temperature $=95$ 
${ }^{\circ} \mathrm{F}$, initial oil saturation $=0.5$, initial water saturation $=$ 0.5 . The shales have water saturation $=1.0$. Initial reservoir pressure $=360$ psia at the formation top depth of $800 \mathrm{ft}$. The reservoir has a 10 degree dip.

6. Two horizontal electrodes are placed at $X=1$ and $X=24$, in the middle sand $(Z=9)$. It is assumed that the horizontal wells serve as the electrodes. The preheating runs were performed at $300 \mathrm{~V}, 2-$ phase $\mathrm{AC}$ at $60 \mathrm{~Hz}$.

7. Constant steam injection rate of $200 \mathrm{Bbls} /$ Day of CWE at Steam Quality $=0.7$ is maintained throughout the simulation period. Coordinates of the injector are $X=13$, $\mathrm{Y}=16$.

8. Producers operates under a constant flowing bottomhole pressure constraint of 14.7 psia.

9. Injector is completed in layers 4 through 9 (bottom three layers) whereas the horizontal producers in Layer $9(\mathrm{X}=1$ and $\mathrm{X}=24$ ) are completed throughout.

10. Relative permeability curves are specified using powerlaw type relations with $\mathrm{S}_{\mathrm{wc}}=0.45, \mathrm{~S}_{\mathrm{org}}=0.12, \mathrm{~S}_{\mathrm{orw}}=0.23$ $\mathrm{S}_{\mathrm{gc}}=0.0, \mathrm{k}_{\mathrm{rocw}}=0.8, \mathrm{k}_{\mathrm{rwro}}=0.12, \mathrm{k}_{\mathrm{rgro}}=0.45, \mathrm{~N}_{\mathrm{w}}=\mathrm{N}_{\mathrm{og}}=$ $=\mathrm{N}_{\mathrm{ow}}=\mathrm{N}_{\mathrm{g}}=2$.

Stone II method is used to compute three-phase relative permeability using two-phase relative permeability data.

\section{Analysis of Electric Resistive (Ohmic) Heating Simulations}

We simulated low frequency electric resistive heating for a period of 6 months. At the end of 6 months the temperature distribution in layer 9 (containing the horizontal electrodes) is shown in Figure 3. Ohmic Heating is a near well-bore effect, with temperatures reaching $400^{\circ} \mathrm{F}$ near the two electrodes. At a distance of 100 feet from the well, the temperature after 6 month of pre-heating is about $170^{\circ} \mathrm{F}$ (or $75^{\circ} \mathrm{F}$ over the initial reservoir temperature of $95^{\circ} \mathrm{F}$ ).

After 6 months of preheating, steam is injected from the central injector, located at $\mathrm{X}=13, \mathrm{Y}=16$. The temperature distribution after 2 months and 1 year of steam injection following electric pre-heating is shown in Figures 4 and 5 respectively. In comparison, the temperature distribution after 1 year of steam injection in a cold reservoir is shown in Figure 6. It is evident from the simulation results that electric preheating allows for a more-uniform and widespread heating of the reservoir. This translates into accelerated production at the beginning and higher cumulative oil during the duration of the simulation. The length of the electrodes, power requirements and time for preheating can be optimized for specific projects. We do not present any optimizations in this paper.

An important consideration in Ohmic Heating simulations is to appropriately handle the effect of water saturation on heating. As the temperature rises in the reservoir, and boiling occurs, the resistivity increases (following Waxman and Smits [34] model presented in Equation 3). This reduces the current and heating decreases (as it is proportional to $\mathrm{I}^{2}$ ). Keeping the temperature below the boiling point of water at reservoir pressure helps in the broader distribution of electric heat.

The presence of shales, having $\mathrm{Sw}=1.0$, also has a significant effect on heating. Figure 7 shows the temperature distribution across the $\mathrm{X}-\mathrm{Z}$ cross-section of the simulation model when shales are present. In comparison to Figure 8 (when shales are absent), the heated zone in Figure 7 , is stretched out or elongated. This happens because the higher conducting shales conduct current further into the reservoir, increasing the heated region. The location of the electrodes with reference to the water-bearing shales can be optimized for best over-all heating.

\section{High Frequency Electromagnetic Heating}

From Maxwell's equations the following simplied expression for average power dissipated in a volume $V$ can be derived:

$$
P_{a v e}=\omega \varepsilon_{o} \varepsilon^{\prime \prime} E^{2} V \quad \text { watts }
$$

or

$\bar{p}=\sigma E^{2} \quad$ watts per cubic meter

where

conductivity $\sigma=\omega \varepsilon_{O} \varepsilon^{\prime \prime}$

and

$\omega=$ radian frequency

$\varepsilon_{O}=$ free space dielectric constant

$\varepsilon^{\prime \prime}=$ loss factor (proportional to the electromagnetic energy absorbed by the porous media)

$E=$ rms electric field intensity in volts per meter.

As electromagnetic energy is absorbed by the porous media, the increase in temperature can be calculated from the following simple equation:

$\sigma E^{2} d t=\rho c_{p} d T$

where

$\rho=$ mass density in $\mathrm{kg} / \mathrm{m}^{3}$

$\mathrm{c}_{\mathrm{p}}=$ specific heat at constant pressure 


$$
\frac{d T}{d t}=\frac{\sigma E^{2}}{\rho c_{p}}
$$

For an imposed electric field $\mathrm{E}$, the rate of temperature increase depends on $\frac{\sigma}{\rho c_{p}}$

The dielectric constant varies with frequency and temperature, an can be measured in the laboratory.

\section{Microwave Heating}

The penetration depth of microwaves is usually small, but for relatively mobile reservoir fluids the microwave energy continuously heats fluids as they are drawn towards the producing well. The microwave antenna can be placed in a drilled hole close to the producing well. A schematic of the microwave heating process is shown in Figure 10. Drilling and completion considerations are discussed in Reference [13].

The microwave energy distribution may be obtained from an analytical solution[14] to the antenna equation. The solution presented here represents the solution for a single point source, and the complete antenna consists of a linear array of these point sources [35]. The energy absorbed by the grid block $\mathrm{i}$ (per unit volume per unit of time) due to the $\mathrm{k}$ 'th point source, $P_{i}^{k}$ is calculated according to the coordinates of the grid block and its relation to the source.

For a block i containing a point source,

$$
P_{i}^{k}=\frac{2 P_{O}^{k} \alpha^{2}}{V} \frac{1}{\left(2 \alpha^{2}\right)}-\vec{r}^{2}+\frac{r}{\alpha}+\frac{1}{2 \alpha^{2}} v^{-2 \alpha r} \sqrt[V]{~}
$$

where

$\alpha=$ attenuation of block $\mathrm{i}$

$\mathrm{r}=$ equivalent radius for block $\mathrm{i}$ (radius of a sphere having the same volume as block i)

$P_{i}^{k} \quad=$ energy absorbed by block $\mathrm{i}$ due to the k'th point source (which is block i)

$P_{O}^{k} \quad=$ antenna power for the k'th point source in the linear array

$\mathrm{V} \quad=$ volume of block $\mathrm{i}$

A 3-D, 3 Phase (oil, water and gas) finite difference simulator TERASIM [35] was used to study the process of microwave heating. A $17 * 17 * 34$ grid block model was created to simulate a 2.5 acre region, which is about 900 feet in thickness. The reservoir permeability and initial oil saturation through a cross section in the middle are shown in Figure 11. We set the microwave antenna (frequency $=0.915 \mathrm{GHz}$ ) in the lower part of the formation (Figure 12) at a distance of about 30 feet from the producing well. Heating the lower layers of the formation has a distinctive advantage because of a combination of factors; higher pressures, the reservoir model has better initial oil saturation in the lower layers (as seen in Figure 11) and that gravity drainage aids in improving recovery.

\section{Features of Simulation Model}

1. The simulation model is a Cartesian, three-dimensional model with 17 x 17 x 34 grid blocks of $\Delta x=19.41 \mathrm{ft}, \Delta \mathrm{y}$ $=22.85 \mathrm{ft}$. The producer is fractured and fracture halfwidth $=400 \mathrm{ft}$. $\Delta \mathrm{z}$ is variable, and the layers containing the microwave source have $\Delta \mathrm{z}=30 \mathrm{ft}$.

2. Oil viscosity at the initial temperature of $100^{\circ} \mathrm{F}$ is 33.11 cp. Viscosity - Temperature Relationship is shown in Table 2.

3. The model represents a heterogeneous layered reservoir with very low permeability. Figure 8 shows a crosssection of the permeability field through the center of the model. $\phi=0.47$. Initial oil saturation is given in Figure 9 .

4. Initial reservoir pressure for simulation $=194$ psia at the formation top depth of $806 \mathrm{ft}$. In the lower layers where the microwave antenna is located, the initial pressure is around 1300 psia.

5. The microwave antenna is assumed to be $30 \mathrm{ft}$ in length and placed at a distance of $30 \mathrm{ft}$ from the producing well.

6. The frequency of the microwave source is $0.915 \mathrm{GHz}$. The power and number of sources was varied - the results presented in this paper are for:

a) Case: $130 \mathrm{~kW}$ source in Layer 30

b) Case: $245 \mathrm{~kW}$ source in Layer 30

c) Case: $360 \mathrm{~kW}$ source in Layer 30

d) Case:6 $60 \mathrm{~kW}$ source in Layer 30 and a second 60 $\mathrm{kW}$ source in Layer 25.

7. Producer operates under a constant flowing bottomhole pressure constraint of 90 psia.

\section{Analysis of Microwave Heating Simulations}

Simulations conducted using the TERASIM [35] microwave simulator show that temperature near the microwave source increases to around $400^{\circ} \mathrm{F}$ (or $300^{\circ} \mathrm{F}$ over the initial reservoir temperature of $\left.100^{\circ} \mathrm{F}\right)$. After 5 years of heating, the temperature at a distance of 60 feet from the source is around $200^{\circ} \mathrm{F}$. Temperature maps are shown in Figures 12 and 13, 
whereas Figure 14 plots the radial distribution of temperature from a $60 \mathrm{~kW}$ microwave source. Figure 15 compares the cumulative oil production for microwave heating scenarios with primary production. When two $60 \mathrm{~kW}$ sources are placed (Case 6) in Layers 25 and 30 respectively, there is an $80 \%$ improvement in cumulative oil recovered over primary production in 10 years. The power requirements after 10 years of heating were estimated to be around $200-250 \mathrm{~kW}$ $\mathrm{hr} / \mathrm{Incremental} \mathrm{Bbl}$ of Oil produced for the various cases discussed.

\section{Some Field Applications of Electromagnetic Heating}

Pizarro and Trevisan[8] presented data from a low frequency electrical heating field test at the Rio Panan field in Brazil. Production increased from $1.2 \mathrm{Bbls} /$ day to $10 \mathrm{Bbls} /$ day after 70 days of applying an average power of $30 \mathrm{~kW}$ across neighboring producing wells (328 feet apart) in a reservoir with rather viscous oil ( $2500 \mathrm{cp}$ at reservoir conditions).

Kasevich et al. [16] performed a laboratory study of RF heating, in which low permeability diatomite samples filled in a 55 gallon drum were heated with an electric monopole. After 49 minutes of heating with a 400 watts and $50.55 \mathrm{MHz}$ source, the temperature rose by $125 \mathrm{C}$. Subsequently a field test was carried out at the North Midway field [16]. The test well was located where the diatomite interval was relatively homogeneous, starting at 500 feet. A mobile RF heating system was assembled around a $25 \mathrm{~kW}, 13.56 \mathrm{MHz}$ generator. The RF applicator was 25 length and placed at a depth of 620 feet, enclosed in a 250 feet RF transparent glass/epoxy composite liner. Borehole temperature measured at 605 feet depth, rose to approximately $220^{\circ} \mathrm{F}$ (approximately $130 \mathrm{~F}$ above formation temperature of $90^{\circ} \mathrm{F}$ ) after 40 hours of RF heating.

Radio frequency field tests carried out in the oil shales of $\mathrm{Utah}^{13}$ showed a good heating potential. A RF power sourcea $40 \mathrm{~kW}$ radio transmitter was used at a frequency of 13.56 $\mathrm{MHz}$. The RF power levels were kept in the range of $5 \mathrm{~kW}$ to $20 \mathrm{~kW}$ and temperatures were recorded in the range of $340^{\circ} \mathrm{C}$ $-400^{\circ} \mathrm{C}$. Two radio frequency field tests in tar sands of $\mathrm{Utah}^{13}$ were carried out in 1981. RF power input to the tar sand test volume varied between 40 and $75 \mathrm{~kW}$ and average temperatures of about $120^{\circ} \mathrm{C}-200^{\circ} \mathrm{C}$ were achieved for the two experiments.

Davison[24] presented field test results of electromagnetic stimulation of Llyodminster Heavy Oil Reservoir ( 11.4 API). Though production response to electrical heating was observed, casing insulation failure led to early termination of the test.

\section{Summary and Conclusions}

We modeled pre-heating a reservoir with thin sands separated by shale layers with two horizontal electrodes, operating at $300 \mathrm{~V}$ and $60 \mathrm{~Hz}$ (2 Phase AC). Low frequency Ohmic Heating is a near well-bore effect, with temperatures increasing by $300^{\circ} \mathrm{F}$ near the two electrodes for the example reservoir. At a distance of 100 feet from the well, the temperature increase after 6 month of pre-heating is about $75^{\circ} \mathrm{F}$. Following steam injection after pre-heating provides a uniform distribution of heat in the reservoir. Simulations show that electrical pre-heating significantly accelerated early production and resulted in better cumulative oil production compared to the non pre-heated case for the duration of the simulations.

We also performed simulations which show that high frequency microwave heating may be used for stimulating oil production in moderately viscous, low permeability reservoirs. The microwave source could be located in a well close to the producer $(\sim 30$ feet $)$ and operate at a frequency close to 1 GHz. Simulations show that a $60 \mathrm{~kW}$ microwave source, could increase formation temperatures by $300^{\circ} \mathrm{F}$ near the source within a year of heating. This results in an $80 \%$ increase in cumulative oil production over primary production when $260 \mathrm{~kW}$ microwave sources are placed in the formation over a period of 10 years.

The different variations of electromagnetic heating: microwave frequency, radio frequency and ohmic heating, may be applied, depending on reservoir and fluid properties. Electrical conductivity increases with increasing water saturation, and for oil sands may be proportional to approximately the square of the saturation. Low frequency ( $60 \mathrm{~Hz}$ ) electric resistive heating could be achieved by applying a potential difference across two electrodes attached to two producing wells in the formation. The electric circuit is completed through the formation, with the in-situ water providing the conductivity. However, electric resistive or ohmic heating is reduced where there is little water content or if the water is heated above its boiling point to form steam. In such cases, higher frequency electromagnetic waves can propagate for much larger distances, and heat regions relatively far from the electrode. A region devoid of water near a severely overheated electrode, presents a very large resistance at $50-60 \mathrm{~Hz}$ while it is easily permits propagation of a high frequency electromagnetic wave.

Another major consideration in Electromagnetic Heating is wellbore power transmission and associated power losses. In addition to heating the formation, the electric current produces heat in the wellbore delivery system. To improve the efficiency of Electromagnetic Heating, it is necessary to keep the power dissipated in the wellbore delivery system to a small fraction of the power dissipated in the formation.

Stroemich et al. [26] have shown that for many common wellbore casings, current levels as low as $100 \mathrm{~A}$ rms cause non-linear magnetization of the wellbore steel. This, in turn 
causes hyestersis power losses in the casing and leads to impedances that are much greater than those observed at low current levels. A good understanding of the electrical properties of insulating materials and their degradation under temperature, pressure and fluids must be known so that current leakage through the electrical insulation may be assessed and maximum allowable wellbore and electrode temperatures may be set. Such precautions would help in minimizing the risks of electromagnetic heating field tests.

\section{References}

1. Marx, J.W. and Langenheim R.H.:"Reservoir Heating by Hot Fluid Injection”, Trans., AIME 216: 312-5, 1959.

2. "Thermal Recovery System Uses Electricity," Pet. Eng. (July 1969) 44.

3. Bleakley, W.B., "Unique Electrothermic Recovery Method Gets Rocky Mountain Test," Oil and Gas Journal, (Dec. 1969), 162-163.

4. Rintoul, B., "Electromagnetic Well Stimulation at White Wolf," Pacific Oil World (Oct. 1986), 10-11.

5. El-Feky, S.A.: "Theoretical and Experimental Investigation of Oil Recovery by the Electrothermic Technique," Ph.D. dissertation, U. of Missouri, Rolla (1977).

6. Killough, J.E. and Gonzalez, J.A.: "A Fully Implicit Model for Electrically Enhanced Oil Recovery," paper SPE 156065 presented at the 1986 SPE Annual Technical Conference and Exhibition, New Orleans, Oct. 5-8.

7. Wattenbarger, R.A. and McDougal, F.W.: "Oil Production Response to In-situ Electrical Heating (ERH)," J. Cdn. Pet. Tech. (Nov.-Dec. 1988) 45-50.

8. Pizzaro, J.O.S. and Trevisan, O. V.: "Electrical Heating of Oil Reservoirs: Numerical Simulation and Field Test Results," paper SPE 19685, proceedings of the 1989 SPE Annual Technical Conference and Exhibition, San Antonio, October 8-11.

9. Harvey, A.H. and Arnold, M.D.: "A radial model for estimating heat distribution in selective reservoir heating," J. Cdn. Pet. Tech. (Oct.-Dec. 1980).

10. Baylor, B.A., Maggard, J.B. and Wattenbarger, R.A.: "Improved Calculation of Oil Production Response to Electrical Resistance Heating (ERH)," paper SPE 20482 proceedings of the 1990 SPE Annual Technical Conference and Exhibition of the Society of Petroleum Engineers held in New Orleans, LA, Sep. 23-26.
11. Todd, J.C. and Howell, E. P.: "Numerical Simulation of in-situ electrical heating to increase oil mobility," J. Cdn. Pet. Tech. (April - June 1978).

12. McGee, B.C.W. and Vermuelen, F.E.: "Electrical Heating with Horizontal Wells, The Heat Transfer Problem," paper SPE 37117 proceedings of the 1996 SPE International Conference on Horizontal Well Technology, Calgary, Canada, 18-20 November 1996.

13. Warren, G. M., G. A. Behie, J. M. Tranquilla, "Microwave Heating of Horizontal Wells in Heavy Oil with Active Water Drive," SPE 37114, 1996 International Conference on Horizontal Well Technology, Calgary, 1820 November, 1996.

14. Abernethy, E. R, "Production Increase of Heavy Oils by Electromagnetic Heating, J. of Canadian Petroleum Technology, July - Sept., 1976, pp 91-97.

15. Bridges, J.E., Krstansky, J. J., Taflove, A. and G. Sresty "The IITRI In Situ RF Fuel Recovery Process", Journal of Microwave Power, Volume 18, No. 1, March 1983.

16. Kasevich, R.S., Price, S.L., Faust, D.L. and Fontaine, M.F. "Pilot Testing of a Radio Frequency Heating System for Enhanced Oil Recovery from Diatomaceous Earth". SPE 28619 presented at the $69^{\text {th }}$ Annual Technical Conference and Exhibition held in New Orleans, LA, USA, 25-28, 1994.

17. Glandt, C.A. and Hsu, C-F., "Electric Preheating in LowInjectivity Tar Sand Deposits". SPE/DOE 24165 presented at the Eight Symposium on Enhanced Oil Recovery held in Tulsa, April 22-24, 1992.

18. Towson, D.E., "The Electric Preheat Recovery Process", The Future of Heavy Crudes and Tar Sands, McGraw Hill Inc., New York (1981) 410-412.

19. Gill, W. "The Electrothermic System for Enhanced Oil Recovery," The Future of Heavy Crudes and Tar Sands, McGraw Hill Inc., New York (1981), 469-473

20. Broz, J.S., Savery, W.T., Bridges, J.E., and Sresty, G.C., "Results from a Preliminary Feasibility Study of Electromagnetic Hot Water Flooding for Tar Sands and Heavy Oils," The Third UNITAR/UNDP International Conference on Heavy Crude and Tar Sands, AOSTRA Publishing, Canada (July 22-31, 1985), 837-845.

21. Schild, A. "A Theory for the Effect of Heating Oil Producing Wells." Petroleum Transactions, AIME, Vol 210, 1957.

22. Amba, S.A., G.V. Chilingar and C.M. Beeson, 
"Application of Electrical Current for Increasing Flow Rate of Oil and Water in Porous Media”, SPE 542.

23. McGee, B.C.W, Vermuellen, F.E. and Yu, L. "Field Test of Electrical Heating with Horizontal and Vertical Wells", Journal of Canadian Petroleum Technology, March 1999, Volume 38, No. 3.

24. Davison, R. J. "Electromagnetic Stimulation of Lloydminster Heavy Oil Reservoirs: Field Test Results”, Paper presented at the CIM/AOSTRA Technical Conference in Banff, April 21-24, 1991.

25. Edelstein, W.A., I.E.T. Iben, O.M.Mueller, E.E. Uzgiris, H.R.Phillipp, and P.B. Roemer "Radiofrequency Ground Heating for Soil Remediation: Science and Engineering", Environmental Progress (Vol 13, No. 4), November 1994.

26. Udell, K.S., "Thermally enhanced removal of liquid hydrocarbon contaminants from soil and groundwater", Subsurface Restoration, C.H. Ward, J.A. Cherry and M.R.Scalf, eds. Ann Arbor Press, Inc., Chelsea, MI, pp 251-271, 1997.

27. Newmark, R.L., Editor, "Dynamic underground stripping project: LLNL gasoline spill demonstration report," Lawrence Livermore National Laboratory, Livermore, CA (UCRL-ID-116964), vol 4, p. 6-50, 1994.

28. Carrigan, C.R. and J.J. Nitao, “A Fully Coupled Model for 3-D, Unsaturated Flow and Transport in Soils Ohmically Heated by A.C. Electrical Potentials", Enviromental Science and Technology, 1998.

29. Nitao, J.J., "User's manual for USNT Module of the NUFT code, version 1.0", Lawrence Livermore National Laboratory Report, Livermore, CA, 67 pages, 1998.

30. Lessor, D.L, L.L. Eyler and P.S. Lowery, "Joule heat calculations for simulations of multielectrode glass melters and in situ vitrification systems," Glastech. Ber., 64, 95-105, 1991.

31. Smith, G.S. and J.D. Nordgard, "Measurement of the Electrical Constitutive Parameters of Materials Using Antennas", IIEE Transactions on Antennas and Propogation, Vol. AP-33, No. 7, July 1985.

32. Fisher, S. T. "Induction Heating in-situ of the solid fossil fuels", Energy Engineering, V81, N5, 1984.

33. Wong, A, V.R. Young, H.L.Spencer, "A Well Completion Design for Electromagnetic Stimulation", presented at the $8^{\text {th }}$ Annual Heavy Oil and Oil Sands Technical Symposium, March 14, 1991.

34. Waxman, M.H. and L.J.M. Smits, "Electrical
Conductivities in oil bearing shaly sands," Soc. Pet. Eng. J. Trans. AIME, 243, 107-122, June 1968.

35. TERASIM Dynamic Reservoir Simulator - Thermal Reservoir Model. User Guide. Duke Engineering and Services.

36. Stroemich, C.P., F.E. Vermuelen, F.S. Chute, and E. Sumbar, "Wellbore Power Transmission for In-Situ Electrical Heating", AOSTRA Journal of Research, 6 (1990), 273.

This work was performed under the auspices of the U.S. Dept. of Energy at UC California/LLNL undercontract no. W-740-5Eng-48. 


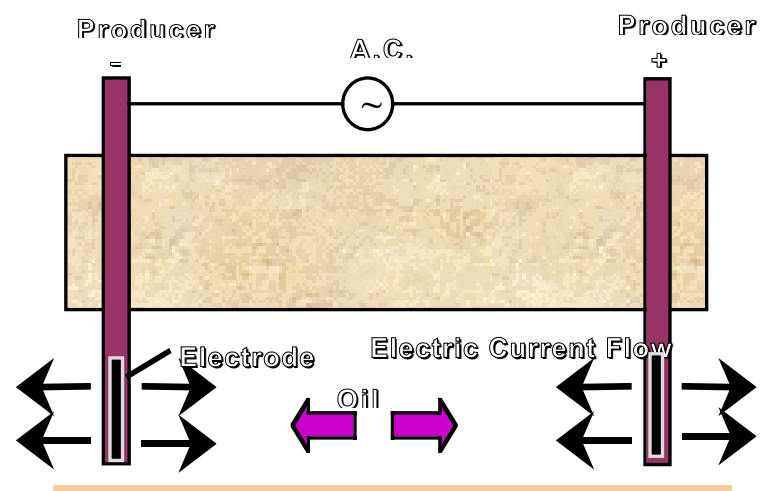

Figure 1. Schematic of Electric Resistive Heating

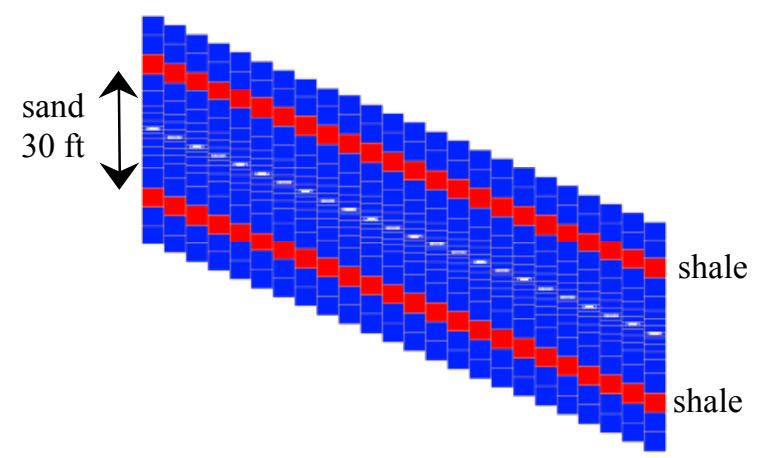

Figure 2. Cross-Section Schematic of Reservoir Modeled for Low Frequency Electric Heating (Example 1).

Table 1. Oil Viscosity-Temperature for Example 1.

\begin{tabular}{|c|c|}
\hline $\begin{array}{c}\text { Temperature } \\
(\mathrm{F})\end{array}$ & $\begin{array}{c}\text { Oil Viscosity } \\
\text { (cp) }\end{array}$ \\
\hline 95 & 9541.0 \\
\hline 100 & 6543.0 \\
\hline 120 & 2230.1 \\
\hline 140 & 866.4 \\
\hline 160 & 410.9 \\
\hline 180 & 213.4 \\
\hline 200 & 122.4 \\
\hline 210 & 90.0 \\
\hline 220 & 74.8 \\
\hline 240 & 47.3 \\
\hline 280 & 23.0 \\
\hline 340 & 9.6 \\
\hline 380 & 7.0 \\
\hline 400 & 5.2 \\
\hline &
\end{tabular}

\begin{tabular}{|c|c|}
\hline 500 & 3.0 \\
\hline 600 & 1.4 \\
\hline 800 & 1.0 \\
\hline 1000 & 0.5 \\
\hline
\end{tabular}

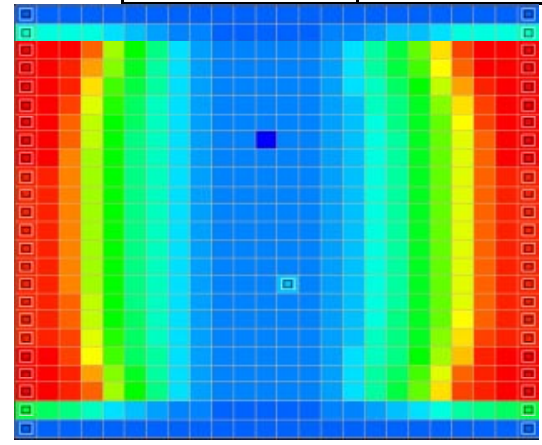

Figure 3. Temperature at 6 months of Preheating (in Layer 9)

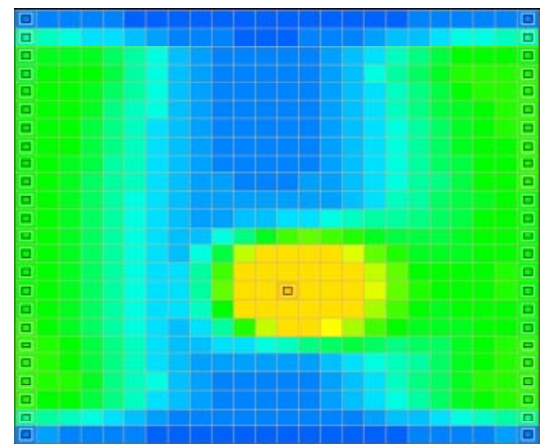

Figure 4. Temperature after 2 months of Steam Injection after 6 months of pre-heating (in Layer 9)

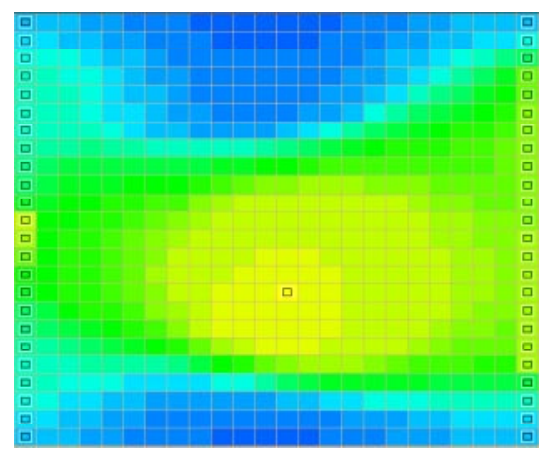

Figure 5. Temperature after 1 year of Steam Injection after 6 months of pre-heating (in Layer 9)

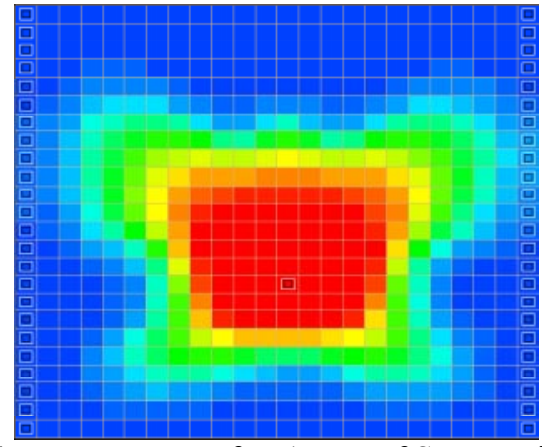

Figure 6. Temperature after 1 year of Steam Injection in a 
cold reservoir.

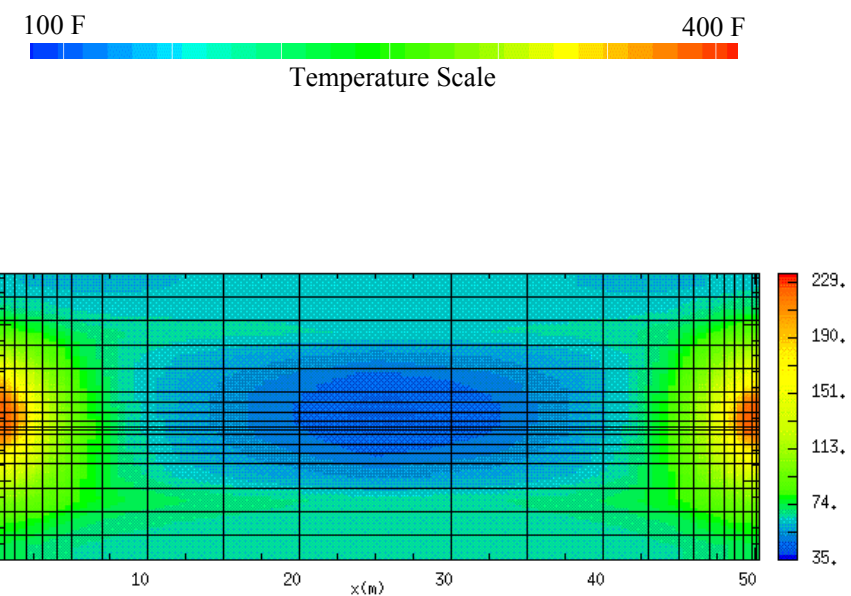

Figure 7. X-Z cross-section of Example 1 showing temperature distribution after 12 months of electric heating.

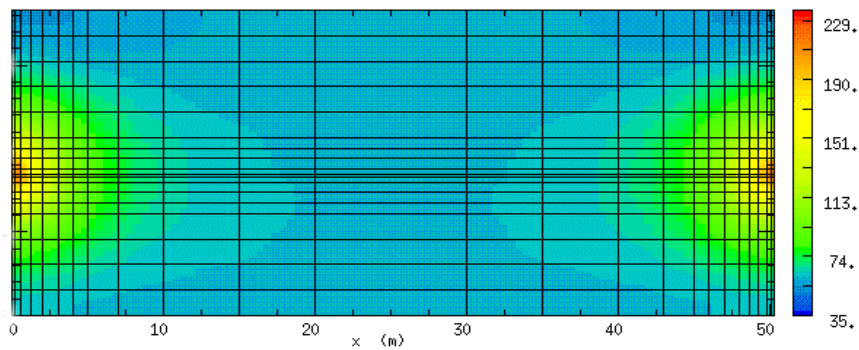

Figure 8. X-Z cross-section of Example 1 (without the shales) showing temperature distribution after 12 months of electric heating.

Cumulative Oil Production

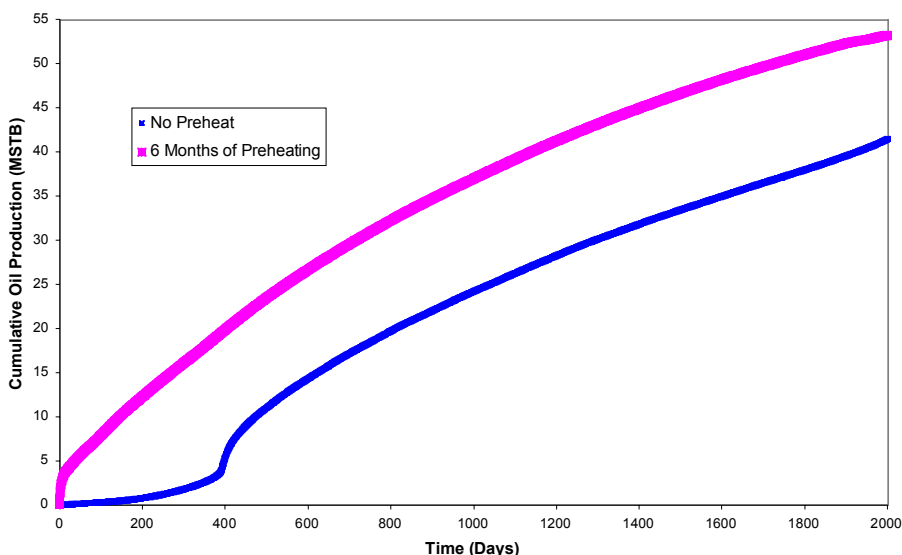

Figure 9. Cumulative Oil Production from Horizontal Wells with and without Preheating

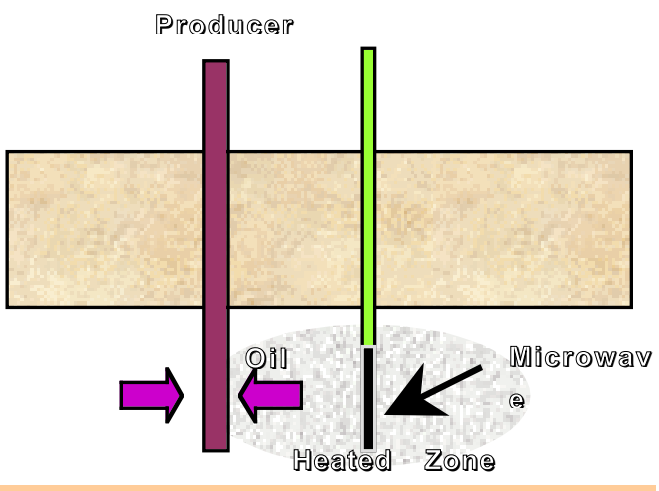

Figure 10. Schematic of Microwave Heating
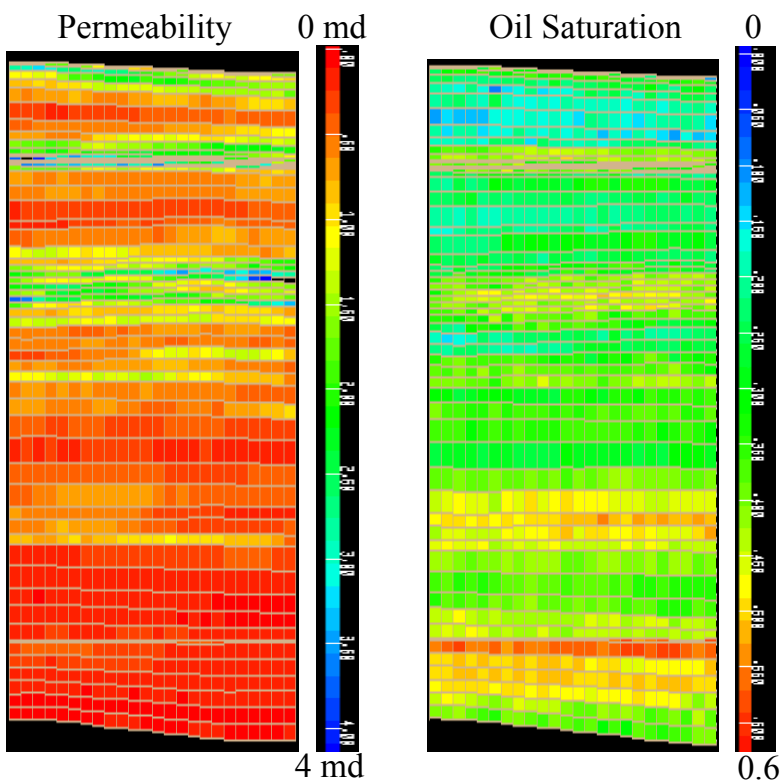

Figure 11. Permeability and Oil Saturation for Example 2.

Table 2. Oil Viscosity-Temperature for Example 2.

\begin{tabular}{|c|c|}
\hline Temperature (F) & $\begin{array}{c}\text { Oil Viscosity } \\
(\mathrm{cp})\end{array}$ \\
\hline 100 & 33.11 \\
\hline 111 & 15.86 \\
\hline 150 & 6.031 \\
\hline 200 & 2.057 \\
\hline 250 & 1.002 \\
\hline 300 & 0.607 \\
\hline 350 & 0.427 \\
\hline 400 & 0.330 \\
\hline 450 & 0.270 \\
\hline
\end{tabular}




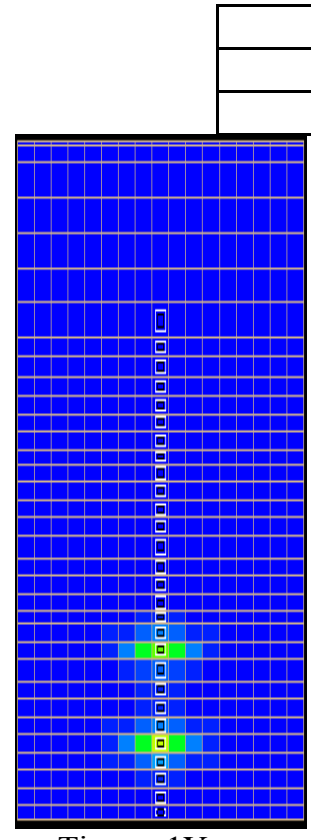

Time $=1$ Year

\begin{tabular}{|l|l|}
\hline 500 & 0.235 \\
\hline 550 & 0.209 \\
\hline 600 & 0.193 \\
\hline
\end{tabular}

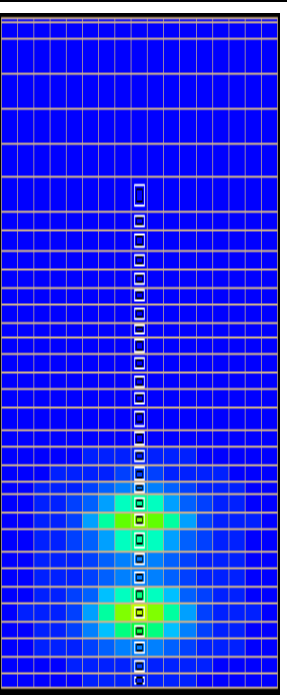

Time 5 Years

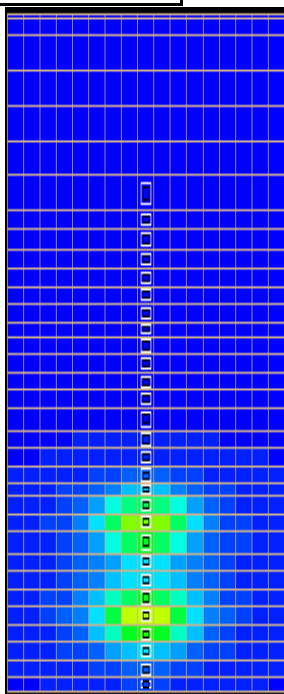

Time $=10$ Years
Figure 12. Temperature Distribution for Case 6: $60 \mathrm{~kW}$ microwave source in Layer 30 and another $60 \mathrm{~kW}$ microwave source in Layer 25.

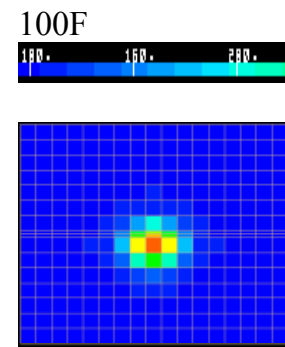

Time $=1$ Year

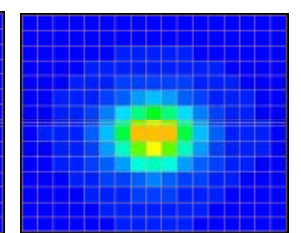

Time 5 Years

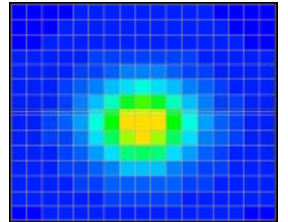

Time $=10$ Years
Figure 13. Temperature Distribution for Case 6 (Layer 30).

Temperature Distribution around Microwave Source

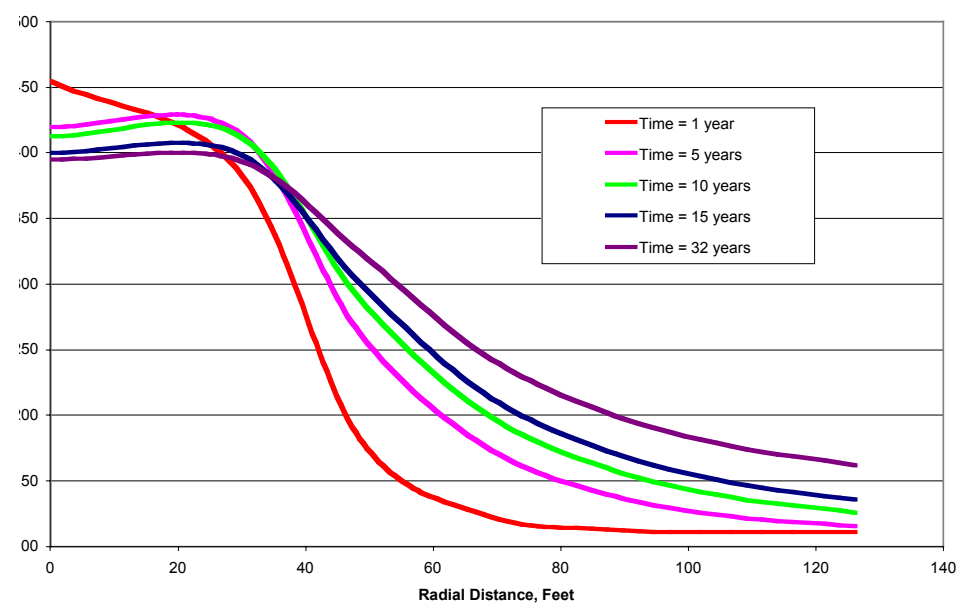

Figure 14. Temperature Distribution around Microwave Soruce (Case 6).

Figure 15. Cumulative Oil Production for Various Scenarios

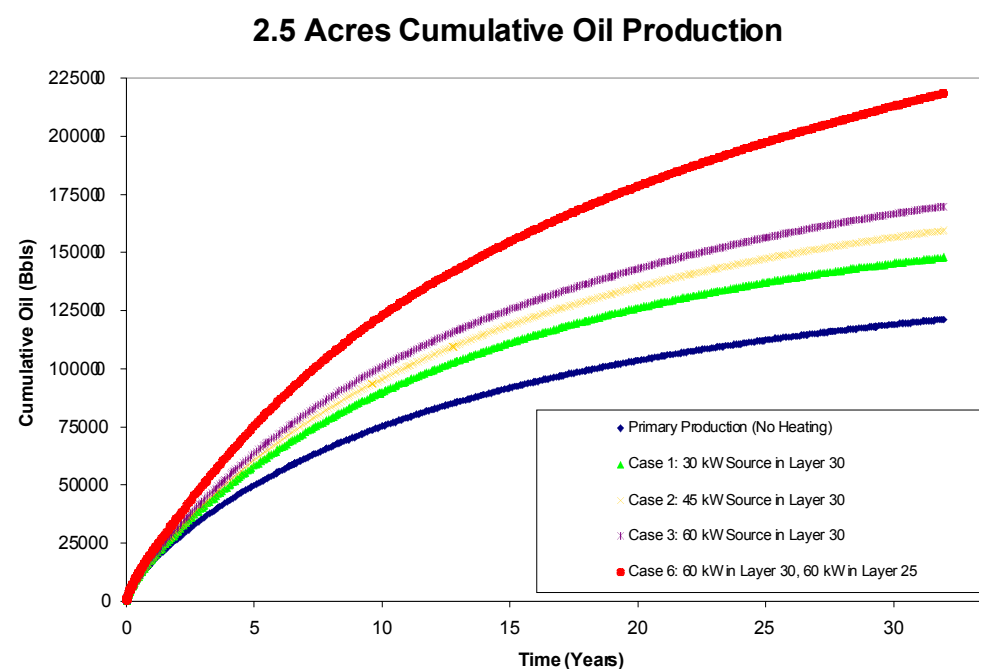

for Example 2. A Base Case with primary production is also provided. 